\title{
A Clinical evaluation of efficacy of Kapikacchu churna (Black seeds) in The management of Klaibya
}

\author{
Research Article
}

\author{
Sharma Tarun ${ }^{1 *}$, Ramamurthy A ${ }^{2}$, Nathani Sumit ${ }^{2}$, Anand Parul ${ }^{1}$ \\ 1. PG Scholar, 2. Assistant Professor, Department of PS Studies in Dravyaguna, \\ National Institute of Ayurveda, Jaipur, Rajasthan, India
}

\begin{abstract}
Healthy sexual functioning plays an essential role in maintaining the harmony and happiness in marital life. The common cause which always prevents a man from enjoying sexual interplay with his female partner is "Klaibya" in Ayurveda and in medical term it is called as Male Sexual Dysfunction (MSD). A special group of disorders of coital performance and sexual intercourse in total, either primary or secondary are grouped in Male Sexual Dysfunction. Male Sexual Dysfunction being common amongst men of invariably all ages, has been recently reported to have affected more than 152 million men worldwide with erectile dysfunction in the year 1995 and it is estimated that this number will rise to approximately 322 million by the year 2025. Keeping these facts in mind, present study is aimed to evaluate the efficacy of Kapikacchu churna (black seeds) in the management of Klaibya. A clinical trial on 15 patients of klaibya was carried out. The trial drug Kapikacchu churna (black seeds) in the dose of 5 gm twice/day with luke warm milk was administered to all the patients for 1 month. The results showed statistically highly significant improvement in total sperm count and rapid linear progressive (RLP) motility of sperms while there were significant results observed in other sexual symptoms and seminal parameters.
\end{abstract}

Keywords: Klaibya, Kapikacchu churna, Male sexual dysfunction, black seeds.

\section{Introduction}

Sex is a physiological basic instinct, but sexual behavior is a spontaneous learned ability. Dharma, Artha, Kama and Moksha are among the four Purusharthas, objectives of life mentioned in Ayurveda. The achievement of each of these is the basic need of every individual. The concept of Kama reveals that the recreational aspects like pleasure are equally important to its procreation aspects. An apparent disparity between the subjective sense of pleasure and objective performance is always present. Healthy Sexual functioning plays essential role in maintaining the harmony and happiness in marital life. It provides a media to express love, which is the base for all sort of creative activities, the absence of which hampers the marital relationship leaving to frustration sometimes, may end into divorce and causes inadequacy in performing the routine duties. The male sexual dysfunction (MSD) includes all sorts of disturbances of coital performance and sexual congress in male. All these conditions have been elaborately described as 'Klaibya' in Ayurvedic classics.

\footnotetext{
*Corresponding Author:

Tarun Sharma

PG Scholar, Department of P.G. Studies in

Dravyaguna, National Institute of Ayurveda,

Jaipur, Rajasthan, India

Email: tarunsharma1286@gmail.com,

Phone No: +91 - 9887701733
}

Acharya Charaka has given a very justified definition of "Klaibya" as-"A person even on having sexual desire and a willing partner, is not able to have coitus with her due to lack of erection or lack of rigidity of the penis. Even if he manages to have erection, his anxiety will cause attacks of dyspnoea and profuse sweating and his attempts to have sex will result in a failure (1).

MSD is a broad spectrum terminology, under which erectile dysfunction is one of the major components. $20 \%$ men under the age 40 years are affected by erectile dysfunction, which is the commonest hidden cause of breaking marital relation in Indian society and $50 \%$ men above the age of 40 years suffer ED, which is of great concern. It has been recently reported to have affected more than 152 million men worldwide with erectile dysfunction in the year 1995 and it is estimated that this number will rise to approximately 322 million by the year 2025.The great increases will be in the developing world, that is Africa, Asia and South America (2).

Hence, it is the need of the hour to conduct researches in finding out safe, easily available, economic and potent medicines for the management of Klaibya. Kapikacchu (Mucuna pruriens (L.) DC.) is such a type of easily available herb that can be found throughout India. It is used as Balya, Vrishya, Brihankaraka and for Vata shaman (3). It is described as Vrishya Dravya in Samhita (4) as well as Nighantus (3). It's seeds are used for the purpose of Vrishya Karma. Hence, the drug was selected to manage the Klaibya. 
Aims and Objectives

1. To evaluate the efficacy of Kapikacchu churna (black seeds) in the management of Klaibya.

2. To provide low cost and effective treatment.

\section{Materials and Methods \\ Collection of Drug:}

Black seeds of Kapikacchu were collected from field after proper identification. The authentication of raw drugs was done in the Botany Department of Rajasthan University. Seeds were purified, dried, powdered and taken for further study.

\section{Selection of patients:}

For the present study, 15 male patients fulfilling the clinical criteria for diagnosis of Klaibya (MSD) were selected from OPD of National Institute of Ayurveda Hospital and Seth Soorajmal Bambaiwala Hospital, Jaipur irrespective of religion, cast, occupation etc.

\section{Inclusion criteria:}

- Male patients in the age of 20-60 years.

- Male patients having sign and symptoms of klaibya

Exclusion criteria:

- Patients below 20yrs and above 60yrs.

- Patients with chronic disease like severe hypertension, IHD, COPD, etc.

- Patients with primary and secondary azoospermia.

- Patients having any sexually transmitted diseases.

- Erectile dysfunction due to nerve damage ex. Accidental injury like spinal cord injury and due to surgery of colon, prostate, bladder and rectum.

\section{Method of study (protocol of Study):}

The study was cleared by the Institutional Ethics Committee. Written informed consent was taken on prescribed format from each patient willing to participate before the start of study. They are briefed about merits and demerits of research plan before taking consent. Patients were free to withdrawal from the study at any time without giving any reason. A detailed case sheet was prepared incorporating Ayurveda as well as modern parameters. Observations were made according to the standard Ayurveda parameters selected and findings were recorded in well-designed case sheet.

\section{Concept of management:}

The selected patients were given Kapikacchu churna (black seeds), in the dose of 5 gm twice/day with luke warm milk for a period of 1 month.

\section{Criteria for assessment:}

The assessment of the patients was done based on subjective as well as objective criteria during the course of trial. The final assessment was done on the basis of the both parameters and by comparing the laboratorial investigation before and after the treatment.

\section{Subjective criteria:}

The International Index of Erectile Function 15 items (IIEF-15) was used at baseline day, day 15 and day 30. IIEF-15 questionnaire (5) was adopted to rule out the sexual problems in the individual and for the assessment of the result.

Objective criteria:

Semen analysis was done on baseline and final day of study.

\section{Observations and Results \\ Demographic profile}

A majority of Klaibya patients i.e $(53.33 \%)$ were in the age group of $20-30$ years, $73.33 \%$ of the patients belonged to Hindu religion, $40 \%$ were educated up to graduation, $40 \%$ belonged to middle class, $86.66 \%$ were living in urban areas and $60 \%$ patients had the history of having mixed food habit. A major proportion of the patients i.e $53.33 \%$ of the patients were involved in field work. $73.33 \%$ patients had sound sleep and 53.33\% patients had the addiction of tea and few patients had the history of smoking, tobacco and alcohol consumption.

In this study, majority of patients i.e $53.33 \%$ patients were of Vatta-Pitta type of Sharirika Prakriti whereas $60 \%$ patients were of Tamasika type of Mansika Prakriti. The maximum number of patients had Manda Agni (40\%), Kroora Kostha (60\%), Madhyama Sara (60\%), Madhyama Samhanana (80\%), Madhyama Pramana (80\%), Madhyama Satmya (66.66\%), Avara Sattva (53.33\%), Madhyama Ahara Shakti (60\%) and Madhyama Vyayama Shakti (40\%).

\section{Results:}

All the Results were calculated by using Software: InStat GraphPad 3.

For Nonparametric Data Wilcoxon matchedpairs signed ranks test is used while for Parametric Data Paired' $t$ ' Test is used and results Calculated in each group.

The results were considered as bellow-

Insignificant/

Non significant

Significant

: $\mathrm{P}>0.05$

Highly significant

: $\mathrm{P}<0.05$

: $\mathrm{P}<0.01, \mathrm{P}<0.001, \mathrm{P}<0.0001$

\section{Effect of Therapy on Erectile function score:}

The mean Score before treatment was 13.26 which increase upto 16.53 after treatment, with $\mathrm{SD} \pm 0.96$ giving a relief of $24.66 \%$ which was statistically highly significant $(p<0.0001)$.

\section{Effect of Therapy on Orgasmic function score:}

The mean Score before treatment was 7.60 which increased upto 8.13 after treatment, with $\mathrm{SD} \pm 0.74$ giving a relief of $6.97 \%$ which was statistically significant $(p<0.05)$.

\section{Effect of Therapy on Sexual desire score:}

The mean Score before treatment was 5.20 which increased upto 7.53 after treatment, with $\mathrm{SD} \pm 1.23$ giving a relief of $44.80 \%$ which was statistically highly significant $(p<0.0001)$. 
ISSN: 0976-5921

Sharma Tarun et.al., A clinical evaluation of efficacy of Kapikacchu churna (Black seeds) in the management of klaibya

Effect of Therapy on Intercourse satisfaction score:

The mean Score before treatment was 4.53 which lowered down to 3.86 after treatment, with $\mathrm{SD} \pm 1.39$ giving a relief of $14.79 \%$ which was statistically non-significant $(\mathbf{p}>\mathbf{0 . 0 5})$.

Effect of Therapy on Overall satisfaction score:

The mean Score before treatment was 4.20 which increased upto 4.80 after treatment, with $\mathrm{SD} \pm 0.82$ giving a relief of $14.28 \%$ which was statistically significant $(\mathbf{p}<\mathbf{0 . 0 5})$.

Table no.1: showing effect of therapy on subjective parameters (wilcoxon matched paired single ranked test)

\begin{tabular}{|c|c|c|c|c|c|c|c|c|}
\hline \multirow{2}{*}{ Variable } & \multicolumn{2}{|c|}{ Mean } & \multirow{2}{*}{$\begin{array}{l}\text { Mean } \\
\text { Diff. }\end{array}$} & \multirow{2}{*}{$\begin{array}{c}\% \\
\text { Relief }\end{array}$} & \multirow{2}{*}{$\mathrm{SD} \pm$} & \multirow{2}{*}{$\mathrm{SE} \pm$} & \multirow{2}{*}{ p value } & \multirow{2}{*}{$\mathbf{S}$} \\
\hline & BT & $\overline{\mathrm{AT}}$ & & & & & & \\
\hline Erectile function & 13.26 & 16.53 & 3.27 & $24.66 \%$ & 0.96 & 0.24 & $<0.0001$ & HS \\
\hline $\begin{array}{l}\text { Orgasmic } \\
\text { function }\end{array}$ & 7.60 & 8.13 & 0.53 & $6.97 \%$ & 0.74 & 0.19 & $<0.05$ & $\mathrm{~S}$ \\
\hline Sexual desire & 5.20 & 7.53 & 2.33 & $44.80 \%$ & 1.23 & 0.31 & $<0.0001$ & HS \\
\hline $\begin{array}{l}\text { Intercourse } \\
\text { satisfaction }\end{array}$ & 4.53 & 3.86 & 0.67 & $14.79 \%$ & 1.39 & 0.36 & $>0.05$ & NS \\
\hline $\begin{array}{l}\text { Overall } \\
\text { satisfaction }\end{array}$ & 4.20 & 4.80 & 0.60 & $14.28 \%$ & 0.82 & 0.21 & $<0.05$ & $\mathrm{~S}$ \\
\hline
\end{tabular}

(HS: Highly Significant S: Significant $\quad$ NS: Non Significant)

Graph no. 1

\section{Fig. showing effect of Therapy in Subjective Parameters}

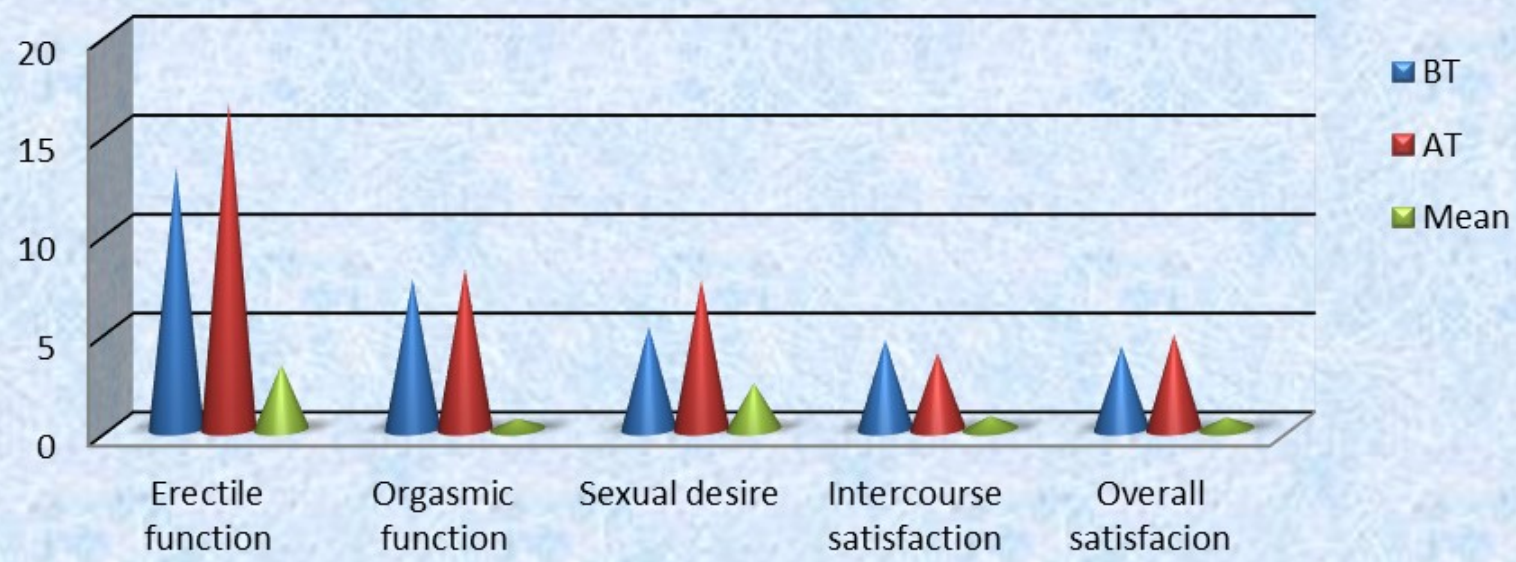

Table no.2: showing effect of therapy on seminal parameters (objectives parameters): (paired' $t$ ' test)

\begin{tabular}{|l|l|l|l|l|l|l|l|l|l|}
\hline \multirow{2}{*}{ Variable } & \multicolumn{2}{|c|}{ Mean } & $\begin{array}{c}\text { Mean } \\
\text { Diff. }\end{array}$ & \% Relief & SD \pm & SE \pm & t value & P value & S \\
\cline { 2 - 9 } & BT & AT & & & & & & \\
\hline $\begin{array}{l}\text { Semen volume } \\
\text { (in ml.) }\end{array}$ & 2.36 & 2.63 & 0.27 & $11.44 \%$ & 0.59 & 0.15 & 1.740 & $>0.05$ & NS \\
\hline Semen pH & 7.63 & 7.74 & 0.11 & $1.44 \%$ & 0.43 & 0.11 & 0.960 & $>0.05$ & NS \\
\hline $\begin{array}{l}\text { Total Sperm } \\
\text { count } \\
\text { (million/ml) }\end{array}$ & 20.00 & 27.66 & 7.66 & $38.30 \%$ & 4.95 & 1.27 & 5.996 & $<0.0001$ & HS \\
\hline RLP (in \%) & 39.33 & 45.33 & 6.00 & $15.25 \%$ & 4.30 & 1.11 & 5.392 & $<0.0001$ & HS \\
\hline SLP (in \%) & 20.00 & 20.33 & 0.33 & $1.65 \%$ & 4.41 & 1.14 & 0.292 & $>0.05$ & NS \\
\hline NP (in \%) & 15.66 & 12.00 & 3.66 & $23.37 \%$ & 4.41 & 1.14 & 1.310 & $<0.05$ & S \\
\hline IM (in \%) & 25.33 & 22.33 & 3.00 & $11.84 \%$ & 4.14 & 1.06 & 2.806 & $<0.05$ & S \\
\hline
\end{tabular}

(RLP-Rapid linear progressive, SLP- Sluggish linear progressive, NP- Non progressive, IM- Immotile) 


\section{Fig. showing effect of Therapy in Objective Parameters}

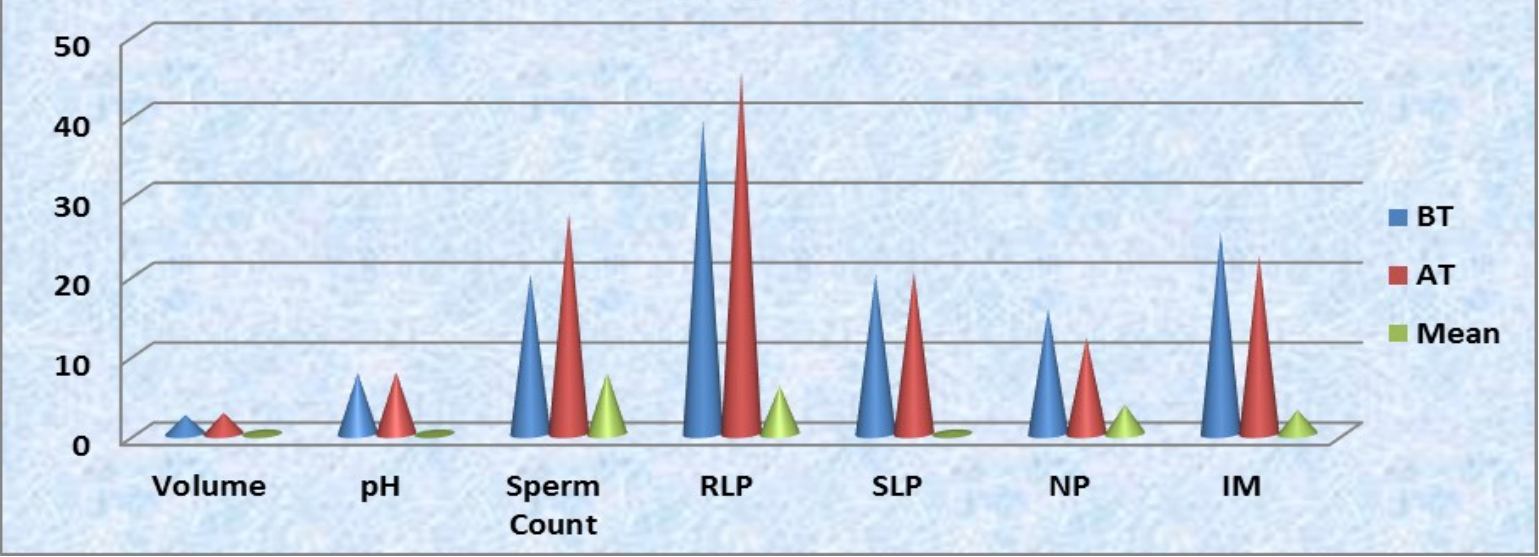

Effect of Therapy on Semen volume Score:

The mean Score before treatment was 2.36 which increased upto 2.63 after treatment, with $\mathrm{SD} \pm 0.59$ giving an improvement of $11.44 \%$ which was statistically non-significant $(\mathbf{P}>\mathbf{0 . 0 5})$.

\section{Effect of Therapy on Semen pH Score:}

The mean Score before treatment was 7.63 which increased upto 7.74 after treatment, with $\mathrm{SD} \pm 0.43$ giving an improvement of $1.44 \%$ which was statistically non-significant $(P>0.05)$.

\section{Effect of Therapy on Total Sperm Count Score:}

The mean Score before treatment was 20.00 which increased upto 27.66 after treatment, with $\mathrm{SD} \pm 4.95$ giving an improvement of $38.30 \%$ which was statistically highly significant $(\mathrm{P}<\mathbf{0 . 0 0 0 1})$.

\section{Effect of Therapy on RLP Score:}

The mean Score before treatment was 39.33 which increased upto 45.33 after treatment, with $\mathrm{SD} \pm 4.30$ giving an improvement of $15.25 \%$ which was statistically highly significant $(\mathrm{P}<\mathbf{0 . 0 0 0 1})$.

\section{Effect of Therapy on SLP Score:}

The mean Score before treatment was 20.00 which increased upto 20.33 after treatment, with $\mathrm{SD} \pm 4.41$ giving an improvement of $1.65 \%$ which was statistically non-significant $(P>0.05)$.

\section{Effect of Therapy on NP Score:}

The mean Score before treatment was 15.66 which lowered down to 12.00 after treatment, with $\mathrm{SD} \pm 4.41$ giving an improvement of $23.37 \%$ which was statistically significant $(\mathbf{P}<\mathbf{0 . 0 5})$.

\section{Effect of Therapy on IM Score:}

The mean Score before treatment was 25.33 which lowered down to 22.33 after treatment, with $\mathrm{SD} \pm 4.14$ giving an improvement of $11.84 \%$ which was statistically significant $(\mathrm{P}<\mathbf{0 . 0 5})$.

\section{Discussion}

The demographical profile of present study reveals that Klaibya is prevailing in the age group of 20 -30 years. On an average, it is observed that active sexual life begins at 25 years and after a series of satisfactory sexual acts, due to presence of anxiety, mental stress and strain, it is more prevalent in the age group 20-30, and the sexual behaviour is greatly affected which results in Sexual dysfunction or Infertility. Maximum numbers of patients were from graduation group. The probable cause may be that in this period people are Keener to their future, so they might be in more stress hence leading to Klaibya. Maximum numbers of patients were from the Middle class community. Middle class cannot afford current costly diagnostic test and drug treatment hence they prefer Government Hospitals where in the drug treatment and the tests are at very affordable cost or almost free. Probably because of the above reason, such category patients were found more. Maximum patients belonged to urban habitat. Hence it can be deduced that sedentary lifestyle predominant in urban habitat is more likely to precipitate the disease.

Mixed diet is the main reason for increase of Raja and Tama Mansika Dosha causing infliction of mind. This finding also makes us aware of the fact that subjects having Raja and Tama Mansika doshas are more prone to develop Klaibya in later stages of their life cycle. Majority of patients belonged to Vata-Pitta prakriti. Vataprakrti Purusha will have Alpa Santana (6). Pittaprakrti Purusha will have Alpa Shukra, Alpa Vyavaya Shakti \& will have Alpa Santata by virtue of Katu-Amla Rasa of Pitta Dosha (7). Hence it may be inferred that either Vata or Pitta association in Sharira Prakriti may make the person more susceptible for Klaibya. Maximum number of patients had Manda Agni and Kroora Koshtha. Kroora Kostha is Vata dominant. So vitiation of Apana Vata has pivot role in the pathogenesis of Klaibya.

Kapikacchu churna (black seeds) provided statistically significant relief in the symptoms of erectile 
function, orgasmic function, sexual desire and overall satisfaction whereas no relief was seen in intercourse satisfaction statistically. Kapikacchu Churna showed statistically significant improvement in total sperm count, rapid linear progressive (RLP) motility, nonprogressive (NP) motility of sperms and in immotile (IM) sperms but improvement of other seminal parameters like semen volume and sluggish linear progressive (SLP) motility of sperms were statistically non-significant.

\section{Probable mode of action of drug}

Kapikacchu seeds possess Madhura Rasa, Guru \& Snigdha Guna, Madhura Vipaka and Sheeta Virya. Guru \& Snigdha Guna and Madhura Rasa have been mentioned as among the six qualities of Vrishya Dravya by Charaka (8). Here Guru, Snigdha Guna and Madhura Rasa are similar to the properties of Shukra (9) hence it definitely increases the Shukra by Samanya Visesha Siddhanta. Kapikacchu has Madhura Rasa which is called as Sharira Satmya, Shukrabhivardhana and Marutaghna, hence it directly increases Shukra, can be used in Shukra dusti specially Vataja Shukradusti. It has Madhura Vipaka which is called as Sristavinmutra and Shukrala hence acts as Vrishya and helps to increase as well as ejaculate Shukra. It has Sheeta Virya, so it can be used to delay ejaculation in case of premature ejaculation. Kapikacchu gives better effect on sexual parameters by alleviating the Vata Dosha due to its Guru and Snigdha Guna, which is the root cause in the manifestation of Klaibya. Thus because of properties like Madhura Rasa and Guru, Snigdha Guna Kapikacchu seeds demonstrate Vrishya, Balya, Brihana, Vajikara actions. It improves vigour and vitality. It increases stamina and libido and acts as a restorative nutrient for the nervous system by supporting healthy production of the sex hormones.

Kapikacchu (Mucuna pruriens) therapy rectifies the perturbed alanine, citrate, GPC, histidine and phenyl alanine content in seminal plasma and improves the semen quality (10). Treatment with $M$. pruriens significantly relieved psychological stress and seminal plasma lipid peroxide levels along with improved sperm count and motility. Treatment also restored the levels of SOD, catalase, GSH and ascorbic acid in seminal plasma of infertile men (11). Above mentioned facts reveal that $M$. pruriens not only reactivates the anti-oxidant defense mechanism, but also helps in the management of stress and improves semen quality.

\section{Conclusion}

The selected drug counteracts the aggravated Vata in sexual dysfunctions, clears the Shukravaha Sroto dusti and improves the sexual arousal and thus can be used as a good remedy in treating the disease. Kapikacchu churna (black seeds) has showed a highly significant increase in erectile function and sexual desire. It has also showed highly significant increase in total sperm count and rapid linear progressive (RLP) motility of sperms. Kapikacchu churna was well tolerated by all the patients and no unwanted effects were observed in any patient during the course of clinical study. As sexual dysfunctions and infertility result from a combination of psychological and physical factors, psychological counselling may help to reduce anxiety and overcome the conditions.

\section{References}

1. Kashinath Shastri and Gorakha Natha Chaturvedi. Charaka Samhita: Chikitsa Sthana 30/155-157, Yonivyapad Chikitsa Adhyaya. Varanasi: Chaukhambha Bharati Academy; reprint 2009. p.863.

2. Rehman S. Erectile dysfunction: Prevalence, incidence and risk factors, Academic Dissertation. University of Tampere; 2004.

3. Shri Krishna Chandra Chunekar, Dr. Ganga Sahaya Pandey editor. Bhava Prakasha Nighantu: Guduchyadi varga. Varanasi: Chaukhambha Bharti Academy; 2013. p.341.

4. Brahmanand Tripathi. Charaka Samhita: Sutra Sthana 27/34, Annapana vidhi Adhyaya. Varanasi: Chaukhamba Surbharti Prakashan; reprint 2008. p.505.

5. Rosen RC, Riley A, Wagner G, Osterloh IH, Kirkpatrick J., Mishra A. The international index of erectile function (IIEF) a multidimensional scale for assessment of erectile dysfunction. Urology. 1997 Jun; 49(6):822-30. Copyright 1997 by Elsevier Science, Inc.

6. Brahmanand Tripathi. Charaka Samhita: Vimana Sthana 8/98, Rogabhisagjitiye Vimana Adhyaya. Varanasi: Chaukhamba Surbharti Prakashan; reprint 2008. p.761.

7. Brahmanand Tripathi. Charaka Samhita: Vimana Sthana 8/97, Rogabhisagjitiye Vimana Adhyaya. Varanasi: Chaukhamba Surbharti Prakashan; reprint 2008. p.760.

8. Pt. Kashinath Shastri and Gorakha Natha Chaturvedi. Charaka Samhita: Chikitsa Sthana 2/4/36, Pumaanjatabaladikam Adhyaya. Varanasi: Chaukhambha Bharati Academy; reprint 2009. p.89.

9. Pt. Kashinath Shastri and Gorakha Natha Chaturvedi. Charaka Samhita: Chikitsa Sthana 2/4/50, Pumaanjatabaladikam Adhyaya. Varanasi: Chaukhambha Bharati Academy; reprint 2009. p.92.

10.Gupta Ashish et al. A proton NMR study of the effect of Mucuna pruriens on seminal plasma metabolites of infertile males. Journal of pharmaceutical and Biomedical Analysis 2011;55:1060-1066. http://dx.doi.org/10.1016/ j.jpba.2011.03.010.

11. Shukla Kamla Kant et al. Mucuna pruriens reduces stress and improves the quality of semen in infertile Men; Advance Access Publication 2010; 7(1):137144. 